\title{
DEPLEÇÃO HETEROGÊNEA DE COMPOSTOS BTEX EM UM SÍTIO CONTAMINADO POR QUEROSENE DE AVIAÇÃO
}

\author{
HETEROGENEOUS DEPLETION OF BTEX COMPOUNDS IN JET \\ FUEL CONTAMINATED SITE
}

Elias Hideo Teramoto ${ }^{1}$; Marco Aurélio Zequim Pede ${ }^{2 ;}$ Kiang Hung Chang $^{3}$

Artigo recebido em: 20/10/2014 e aceito para publicação em: 05/02/2015.

DOI: http://dx.doi.org/10.14295/ras.v29i1.27974

\begin{abstract}
The partitioning of soluble compounds of LNAPL in groundwater is the most common scenario of release of organic contaminants in aquifers. The efficiency of this process depends of several factors, the main interfacial area LNAPL / water. In this work has been established and tested a preliminary conceptual model that includes the processes that govern the partitioning of BTEX compounds in an area contaminated with traped jet fuel in porous media. Empirically it was found that the highest percentage of aromatic compounds LNAPL are situated in the central portion of the source area, where free phase thicknesses in monitoring wells are greatest. Although relations involved in mass transfer are well established, this study is the first to demonstrate from field evidences that there is a more significant mass loss in the marginal region of area source in its central portion. The results presented in this work has strong implications for quantifying the amount of BTEX compounds present in sub-surface, the mass balance in problems involving natural attenuation, the optimization of remediation systems and the mathematical modeling of solute transport.
\end{abstract}

Keywords: Partitioning, LNAPL. BTEX. Jet fuel. Interfacial area water/LNAPL. Free phase.

Resumo: O particionamento de compostos solúveis de LNAPL para a água subterrrânea representa o cenário mais comum de liberação de contaminantes orgânicos nos aquíferos. A eficiência desse processo depende da atuação de vários fatores, sendo o principal a área interfacial LNAPL/água. Neste trabalho foi estabelecido e testado um modelo conceitual preliminar que contemplam os processos que governam o particionamento de compostos BTEX em uma área contaminada por querosene de aviação trapeado no meio poroso. De modo empírico foi constatado que os maiores percentuais de compostos aromáticos do LNAPL estão situados na porção central da área fonte, onde ocorrem as maiores espessuras de fase livre nos poços de monitoramento. Embora as relações envolvidas na transferência de massa sejam bem estabelecidas, este trabalho representa o primeiro a demonstrar a partir de evidêcias de campo que existe uma perda de massa mais expressiva na região marginal da área fonte que em sua porção central. Os resultados apresentados neste trabalho tem fortes implicações para quantificação da quantidade compostos BTEX presente em sub-superfície, balanço de massa em problemas envolvendo atenuação, otimização dos sistemas de querosene de aviação. e modelagem matemática de transporte de solutos.

Palavras-chaves: Particionamento. LNAPL. BTEX. Querosene de aviação. Área Interfacial LNAPL/Água. Fase Livre.

\section{INTRODUÇÃO}

O cenário de contaminação mais frequente por LNAPL (Light Non-Aqueous Phase Liquid), como a gasolina, o diesel e o querosene de aviação, envolve o vazamento de tubulações ou tanques de estocagem em superfície. Se o vaza- mento envolver volumes suficientes de LNAPL, este migrará através da zona saturada até alcançar as vizinhanças do nível d'água (NA). Em condição de NA estático, o LNAPL forma um pool acima da franja capilar. No entanto, em aquíferos

1 LEBAC - Laboratório de Estudo de Bacias. Dep. de Geologia Aplicada, UNESP - Campus de Rio Claro (eh_teramoto@yahoo.com.br)

2 LEBAC - Laboratório de Estudo de Bacias. Dep. de Geologia Aplicada, UNESP - Campus de Rio Claro (mpede@yahoo.com)

2 LEBAC - Laboratório de Estudo de Bacias. Dep. de Geologia Aplicada, UNESP - Campus de Rio Claro (chang@rc.unesp.br) 
não confinados a flutuação cíclica do nível d'água pode induzir a uma redistribuição vertical do LNAPL. A redistribuição de fases no meio poroso é mensurada pelo grau de saturação da água e do LNAPL. Caso a saturação em água seja menor que a saturação irredutível, o óleo escoa e a água permanece presa pelas forças capilares. Da mesma forma, se a saturação em óleo for menor que a saturação residual, a água escoa, mas o óleo não (Chaberneau, 2007). Outro fator que controla a redistribuição de fases é a molhabilidade, que descreve a habilidade relativa de um fluido de recobrir a fase sólida do meio poroso em um sistema multifásico compostos por fluidos imiscíveis. Fluidos mais molhantes tendem a recobrir a fase sólida do aquífero e os fluidos não molhantes tendem a se distribuir no centro do poro (Mercer e Cohen, 1990; Bendient et al, 1999).

Como demonstrado por Lenhard et al. (1993), Kechavarzi et al. (2005), Oostrom et al. (2006) e Chaberneau (2007), Jeong e Chaberneau (2014) quando é registrado o movimento ascendente do nível d'água, parte do LNAPL acompanha a subida do NA e outra parte fica trapeada abaixo do NA, por conta da histerese capilar que reduz sua mobilidade. Na direção oposta, quando o nível d'água cai, a água é drenada do meio poroso e as gotículas de LNAPL se aglutinam aumentando sua saturação e elevando sua mobilidade, de forma que tendem a migrar para os poços de monitoramento, aumentando a espessura de fase livre. O intervalo vertical do aquífero em que o nível d'água oscila e redistribui o óleo é chamado de smear zone. A entrada de água no meio poroso (embebição) ocorre em períodos de ascensão do NA, enquanto sua saída (drenagem) ocorre em períodos de queda do nível d'água. Devido a este comportamento é possível considerar que flutuação sazonal do nível d'água induz a recorrentes e alternados episódios de embebição e drenagem. A Figura 1 ilustra a variação de saturação da água e do LNAPL frente a episódios de drenagem e embebição de água. Entretanto, é possível observar que durante a embebição, a água não atinge $100 \%$ da saturação, pois uma parcela do LNAPL fica aprisionada por forças capilares nos poros como fase residual (Snr). Outro fator a ser considerado é que devido à flutuação do NA a lâmina de fase livre pode não entrar em equilíbrio vertical com o aquífero em suas adjacências, prejudicando a avaliação da saturação e volume de LNAPL no meio poroso. Farr et al. (1990) e Lenhard e Parker (1990), utilizando a Equação de van Genuchten (1980), comprovaram que a saturação em LNAPL acima da interface LNAPL/água (Znw) é função da litologia, da distribuição da pressão capilar, da densidade relativa do LNAPL e da tensão interfacial entre óleo/água. Ambos os trabalhos permitiram estabelecer diferentes perfis de saturação de óleo em função dos diferentes tipos litológicos, espessura de fase livre e das características físicas do LNAPL, os quais estão expostos na Figura 2.

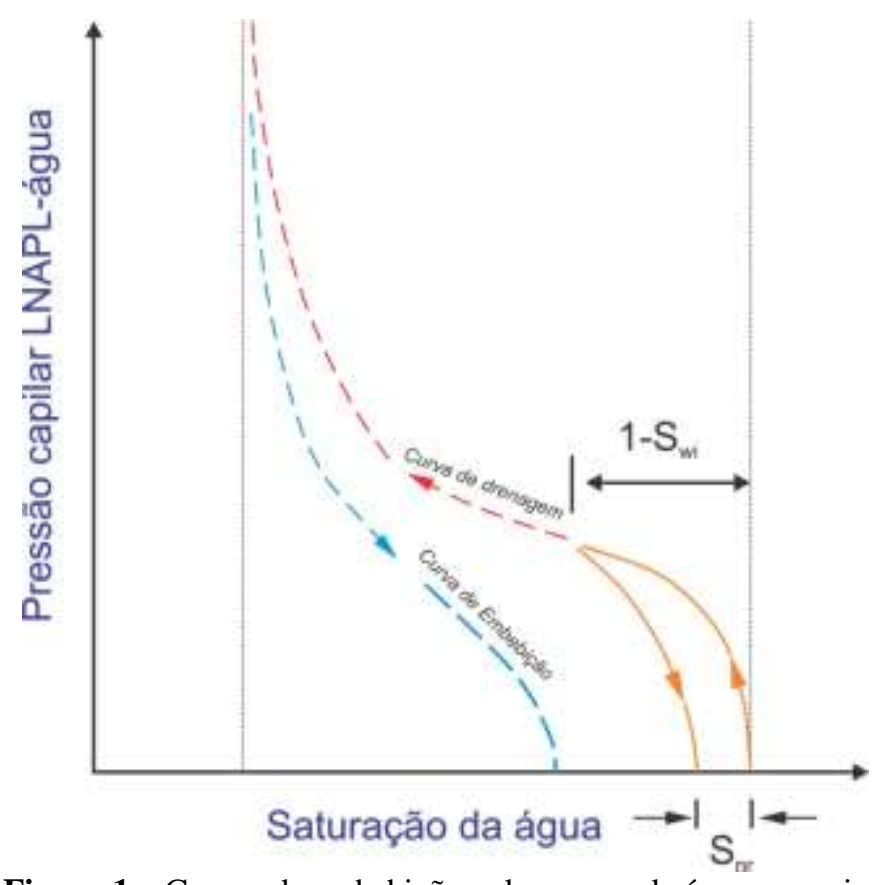

Figura 1 - Curvas de embebição e drenagem da água no meio poroso

Figure 1 - Imbibition and drainage curves of water on the porous medium 


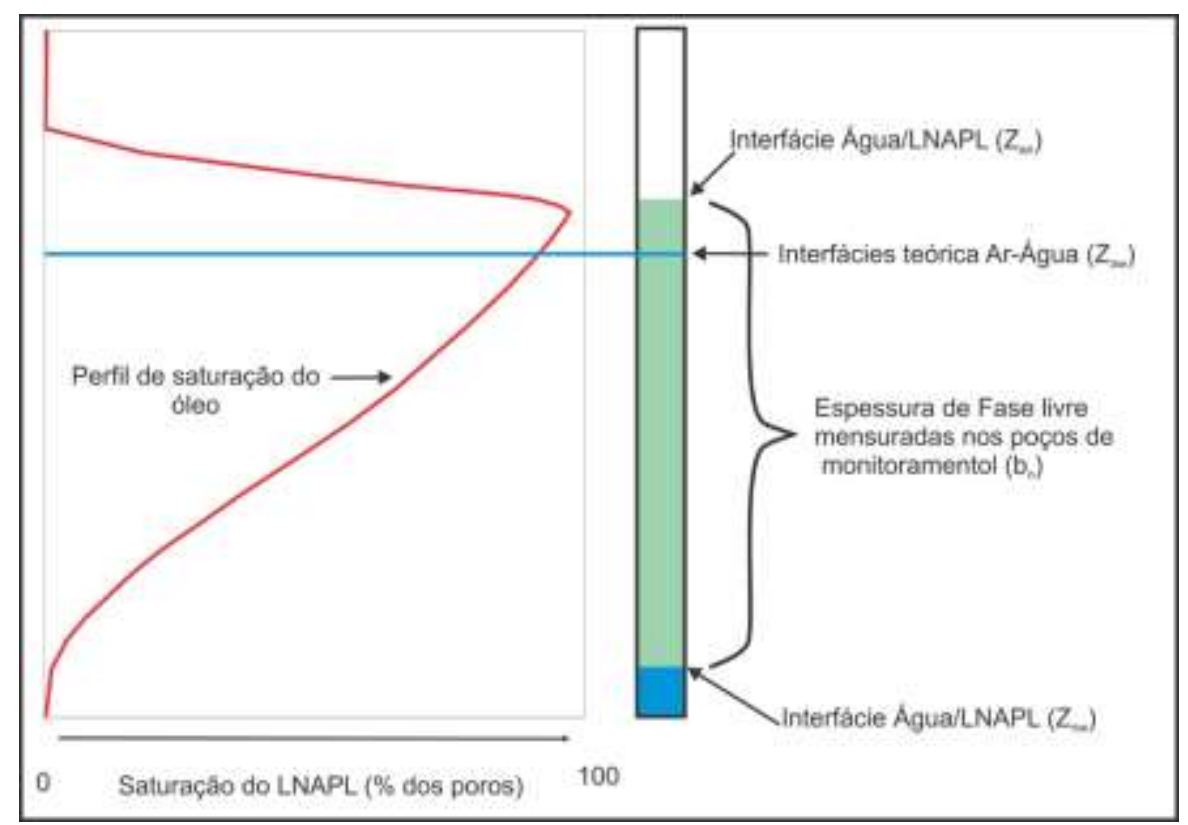

Figura 2 - Perfil de saturação do LNAPL em função da espessura de fase livre nos poços de monitoramento

Figure 2 - Profile of LNAPL saturation as a function of free phase thickness on monitoring wells

Pede (2009) demonstrou, a partir de informações de campo, que o trapeamento do LNAPL, devido à ascensão do nível d'água impede sua remoção por metodologias de remediação baseadas nos sistemas pump-and-treat. $\mathrm{O}$ LNAPL que permanece trapeado é responsável pela contínua liberação de massa de BTEX para a água subterrânea. Desse modo, como demonstrado por Soga et al. (2004), previsões relacionadas às concentrações das plumas requerem o conhecimento da dinâmica que governa a dissolução do LNAPL na área fonte. Os mecanismos que governam a dissolução do NAPL trapeado têm sido objeto de sucessivos estudos experimentais, tendo em vista ser esta a principal responsável pela existência da pluma de compostos BTEX em águas subterrâneas.

A liberação de compostos solúveis do NAPL para a água se dá apenas quando o NAPL está em contato com a água. A área de contato, denominada de área interfacial LNAPL/Água (anw), correspondente à superfície de contato entre o NAPL (fluido não-molhante) e a água (fluido molhante) por unidade volumétrica do aquífero. A massa total transferida entre o LNAPL e a água é calculada multiplicando-se o fluxo de transferência de massa pela área interfacial específica entre as fases (Miller, 1990):

$$
\theta_{\alpha}=\frac{d C_{\alpha}}{d t}=k_{\alpha} a_{\alpha}\left(C_{s \alpha}-C_{\alpha}\right)
$$

Onde: $\theta_{\alpha}$ é a fração volumétrica da fase $\alpha ; \frac{d C_{\alpha}}{d t}$ é a variação de concentração na água em função do tempo; $a_{\alpha}$ é a área interfacial específica entre LNAPL e fase $\alpha\left(\mathrm{cm}^{-1}\right) ; k_{\alpha}$ é o coeficiente de transferência de massa; $C_{\alpha}$ é a concentração vométrica da fase $\alpha ; C_{s \alpha}$ é a concentração na fase $\alpha$ que estará em equilíbrio com o LNAPL.

Com base nessa relação, é possível verificar que a magnitude da transferência de massa do LNAPL para a água está diretamente relacionada à área interfacial específica entre esses dois fluidos, o que impõe a necessidade de se estimar a área interfacial do LNAPL trapeado ou residual para calcular a massa particionada para a água. Diversos autores (Anderson et al., 1992, Brusseau et al., 2009, Held e Celia, 2001, Grant e Gehard, 2007, Bradford e Leij, 1997, Oostrom et al., 2001, Potter et al., 2010, Dodson et al., 2006) propuseram modelos empíricos ou formulações baseadas em princípios termodinâmicos para estimar anw a partir da saturação da água (Sw) e da saturação do LNAPL (Snw).

Embora Brusseau et al. (2009) tenha demonstrado que anw decresce linearmente com o incremento da saturação da água, os demais autores apontaram comportamentos mais complexos, como o apresentado por Potter et al. (2010). Como é possível verificar na Figura 3, a redução da saturação de água, isto é, a elevação na saturação 
do LNAPL, induz a um incremento de anw. A explicação para esse comportamento é que em situações em que a saturação do LNAPL é muito elevada, este se distribui em lentes contínuas, reduzindo a área interfacial LNAPL/água (Figura $4 \mathrm{~A}$ ), ao passo que para que baixas saturações de LNAPL, este se distribui como gotículas descontínuas com elevada área interfacial LNAPL/água (Figura 4 B). Face a este comportamento, é esperado que a massa de BTEX transferida a partir do LNAPL residual ou trapeado seja mais efetiva no caso exposto na Figura 3.

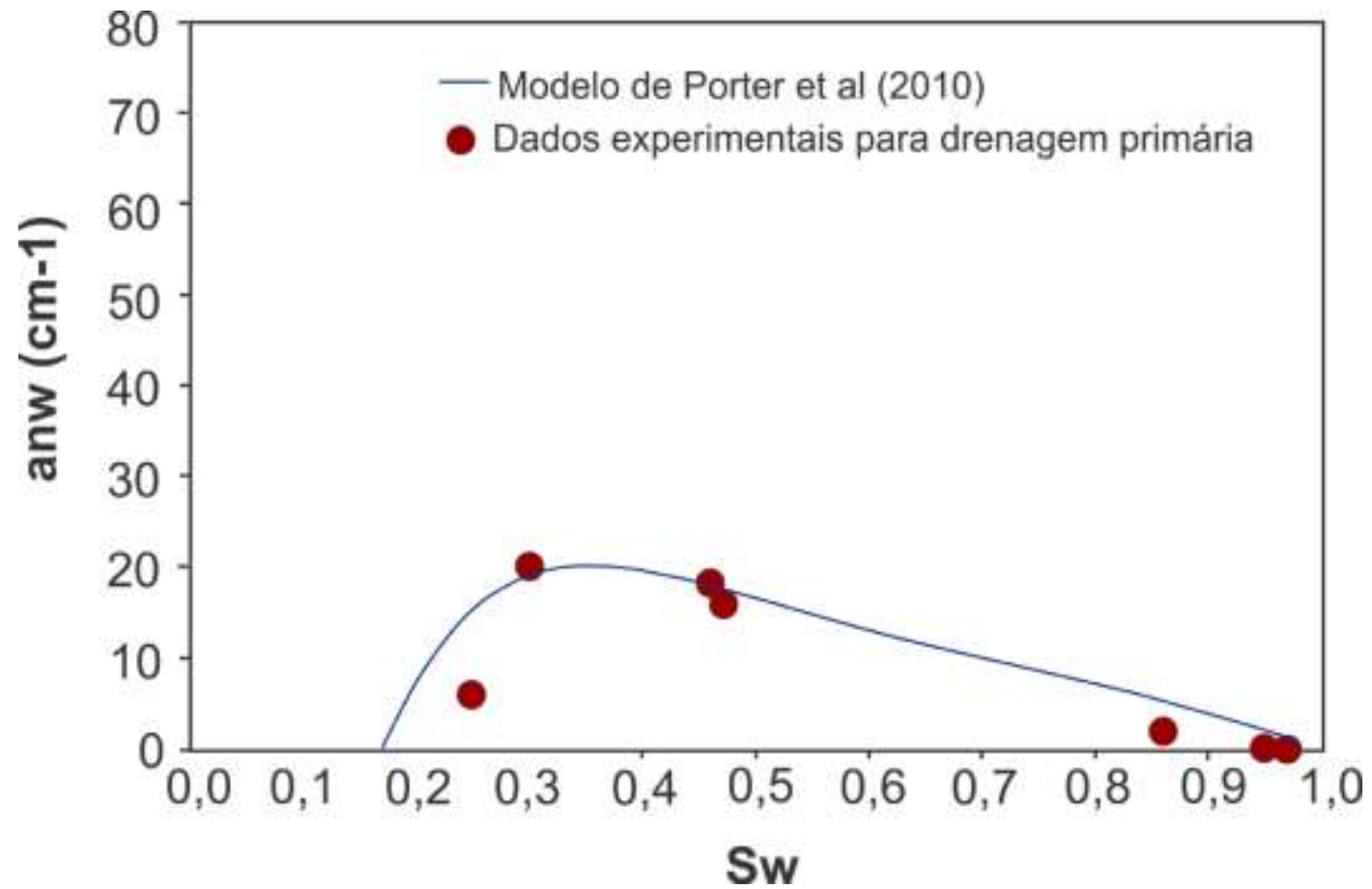

Figura 3 - Ajuste do modelo termodinâmico proposto por Potter et al. (2010) aos dados experimentais de Brusseau et al. (2007), relacionando área interfacial NAPL/água (anw) e saturação da água $(\mathrm{Sw})$

Figure 3 - Thermodynamic model proposed by Potter et al. (2010) and experimental data of Brusseau et al. (2007) showing the relation between NAPL/water interfacial area (ANW) and the water saturation $(\mathrm{Sw})$
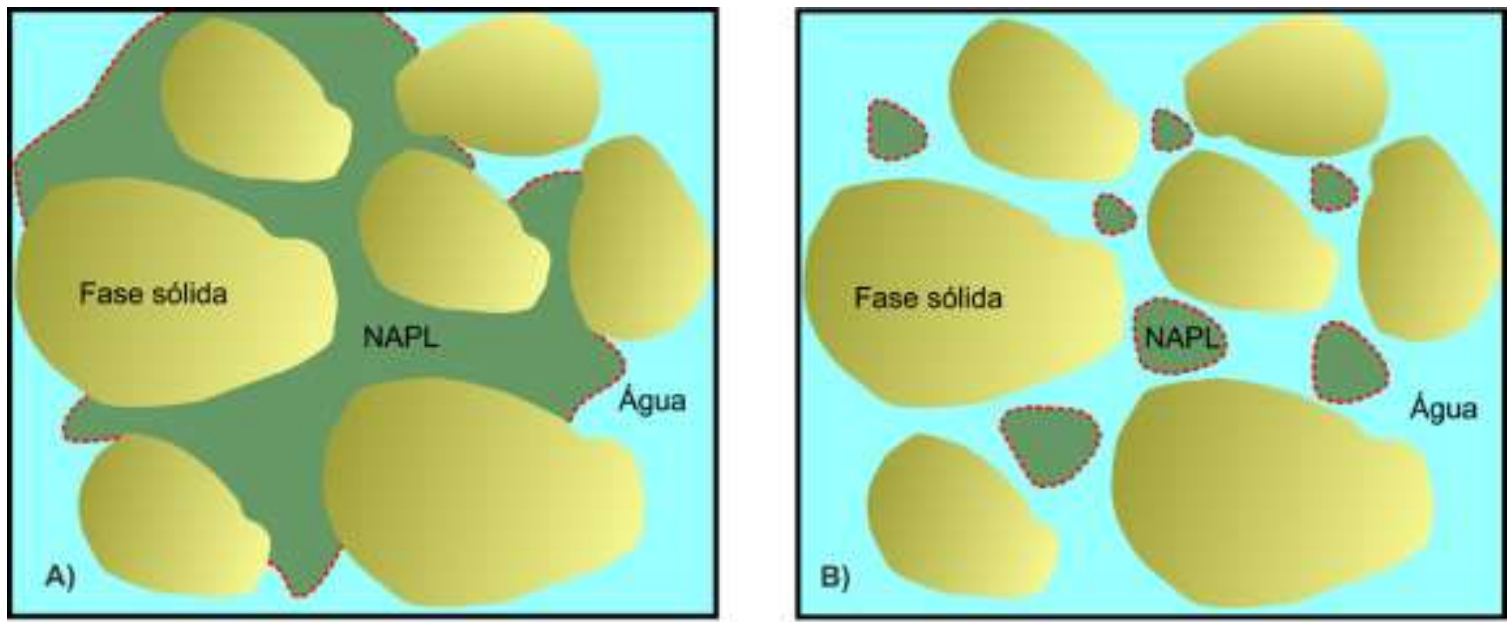

Área interfacial água/NAPL (anw)

Figura 4 -Área interfacial NAPL/água em dois cenários distintos. A) Elevada saturação de LNAPL residual e reduzida área interfacial. B) Reduzida saturação de NAPL e elevada área interfacial

Figure 4 - NAPL/water interfacial area in two distinct scenarios. A) High saturation of residual NAPL and reduced interfacial area. B) Reduced LNAPL saturation and high interfacial area. 
Bradford e Leij (1997) e Chen et al. (2007) verificaram que a área interfacial LNAPL/água decresce durante eventos de embebição e crescem nos eventos de drenagem, o que sugere que as flutuações sazonais do nível d'água promovem variações de anw ao longo do tempo, resultando em variações nas taxas de transferência de massa. É necessário destacar que embora a magnitude da transferência de massa seja controlada pela área interfacial LNAPL/água, a quantidade de BTEX liberado em águas subterrâneas pela dissolução do LNAPL na área fonte é igualmente controlada por outros fatores. Saba e llangasekare (2000) atribuíram a eficiência na transferência de massa à velocidade de fluxo. Adicionalmente, Powers et al. (1994), Brusseau et al. (2009), Dodson et al. (2006) e especialmente Cho e Annable (2005) demonstraram que o tamanho dos grãos que compõem o meio poroso e as características do poros exercem controle na transferência de massa. Por fim, Grant e Gehard (2007) e Bradford e Leij (1997) demonstraram que a história de saturação e drenagem da água no meio poroso também causa impacto na quantidade de massa particionada para a água a partir do LNAPL.

Como descrito por Pede (2009), a espessura de fase livre nos poços de monitoramento, bem como o volume de LNAPL passível de recuperação pelo sistema de remediação pump-and-treat são controlados pela oscilação do nível d'água. A ascensão do NA durante os eventos de recarga gera o trapeamento do óleo, o que implica na redução da fase livre nos poços de monitoramento e a baixa recuperação de óleo. Por outro lado, durante o período em que se observa a queda do nível d'água (evento de embebição), as espessuras de fase livre aumentam nos poços de monitoramento e é registrado aumento na recuperação do volume de óleo. Ainda segundo o referido autor, paralelamente ao sistemas para recuperação de LNAPL foi promovido um programa para monitorar os processos de atenuação natural na área. Wang e Kuo (2014) obteve resultados similares aos descritos por Pede (2009) a partir de experimentos conduzidos em laboratório e demonstrou que durante os eventos de precipitação e elevação do nível d’água as taxas de recuperação do LNAPL declinavam.

Embora os mecanismos envolvendo a diferenciação na saturação do LNAPL e na transferência de massa sejam perfeitamente compreendidas, inexistentes trabalhos demonstrando a depleção diferenciada de compostos BTEX no LNAPL. Ressalta-se ainda que os resultados presentes na literatura baseiamse em experimentos laboratoriais e dada a abrangência de campo, existem heterogeneidaes geológicas que condicionam condições e comportamentos diferenciados. $\mathrm{O}$ estabelecimento das relações entre a quantidade de LNAPL no meio poroso e o comportamente da fase dissolvida deve contemplar a análise conjunta de muitos parâmetros, normalmente não analisados simultaneamente. Adicionalmente, análises de tendência temporal, necessárias para o entendimentos dos fenômenos aqui discutidos, deve conter informações oriundas de uma longa série histórica advindos de um monitoramento contínuo.

O monitoramento empreendido na área de estudo indica que existem amplas diferenças nas tendências de depleção dos compostos monoaromáticos na área fonte. Em virtude do contexto apresentado, o objetivo principal deste trabalho é a proposição de um modelo conceitual que contemple os mecanismos que envolvam a transferência de massa de maneira heterogênea na área fonte, permitindo cálculos de balanço de massa mais precisos e aprimoramento dos sistemas de remediação.

\section{2 ÁREA DE ESTUDO}

A área de estudo está localizada na região de Campinas, SP, na porção nordeste do município de Paulínia (Figura 5). Segundo Fernandes (1997), na região de Campinas ocorrem rochas graníticas pré-cambrianas do Embasamento Cristalino, rochas permocarboníferas do Subgrupo Itararé, em grande parte de origem gláciomarinha, rochas intrusivas básicas, juro-cretácicas, relacionadas à Formação Serra Geral, bem como depósitos cenozoicos correlatos à Formação Rio Claros e extensos depósitos aluvionares recentes. 
Modelo conceitual para explicar a depleção heterogênea de compostos btex em uma área contaminada por querosene de aviação

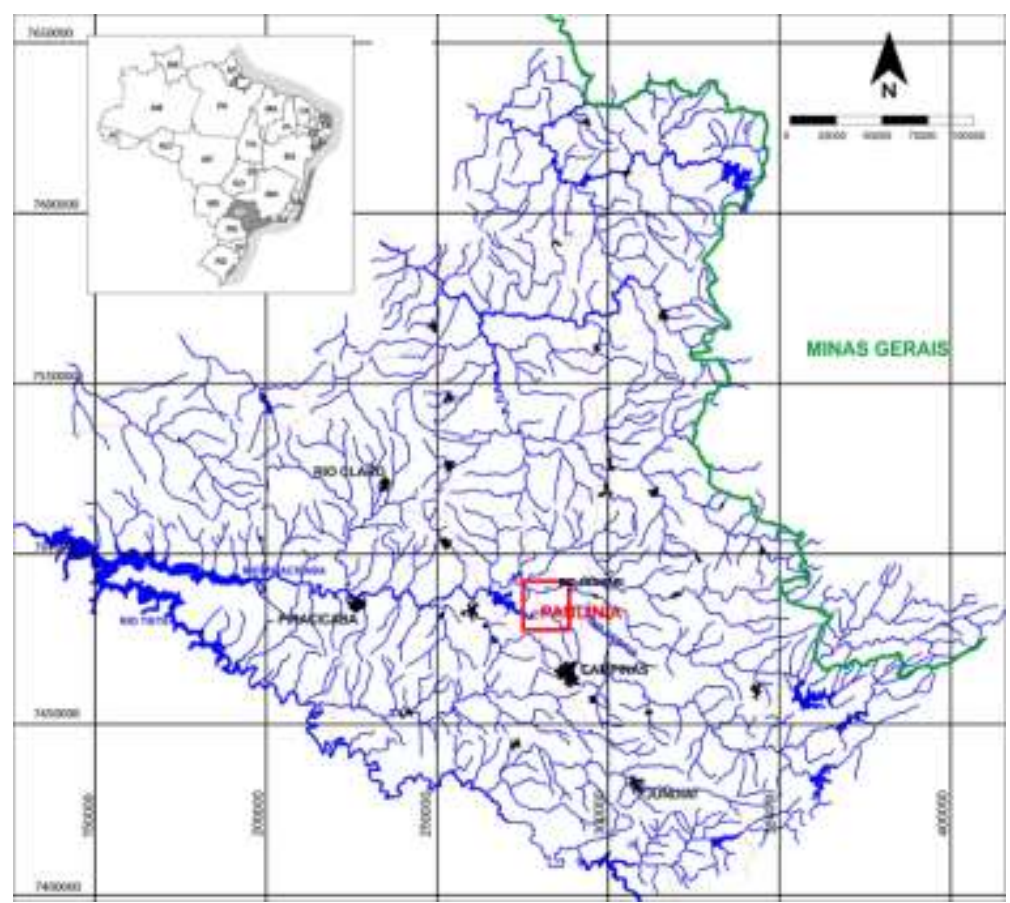

Figura 5- Localização do município de Paulínia (dentro da área destacada em vermelho), onde se encontra a área de estudo

Figure 5 - Location of the municipality of Paulínia, where is placed the study are

\section{METODOLOGIA EMPREGADA}

A fonte da contaminação é o querosene de aviação (QAV) trapeado ou residual, disposto em área de aproxidamente $500 \mathrm{~m}$ de comprimento por $350 \mathrm{~m}$ de largura, com uma pluma dissolvida de BTEX (benzeno, tolueno, etilbenzeno e xilenos) pouco expressiva. Atualmente a área de estudo possui 104 poços de monitoramento empregados para o sistema de extração multifásica e 20 poços de bombeamento (Figura 6).

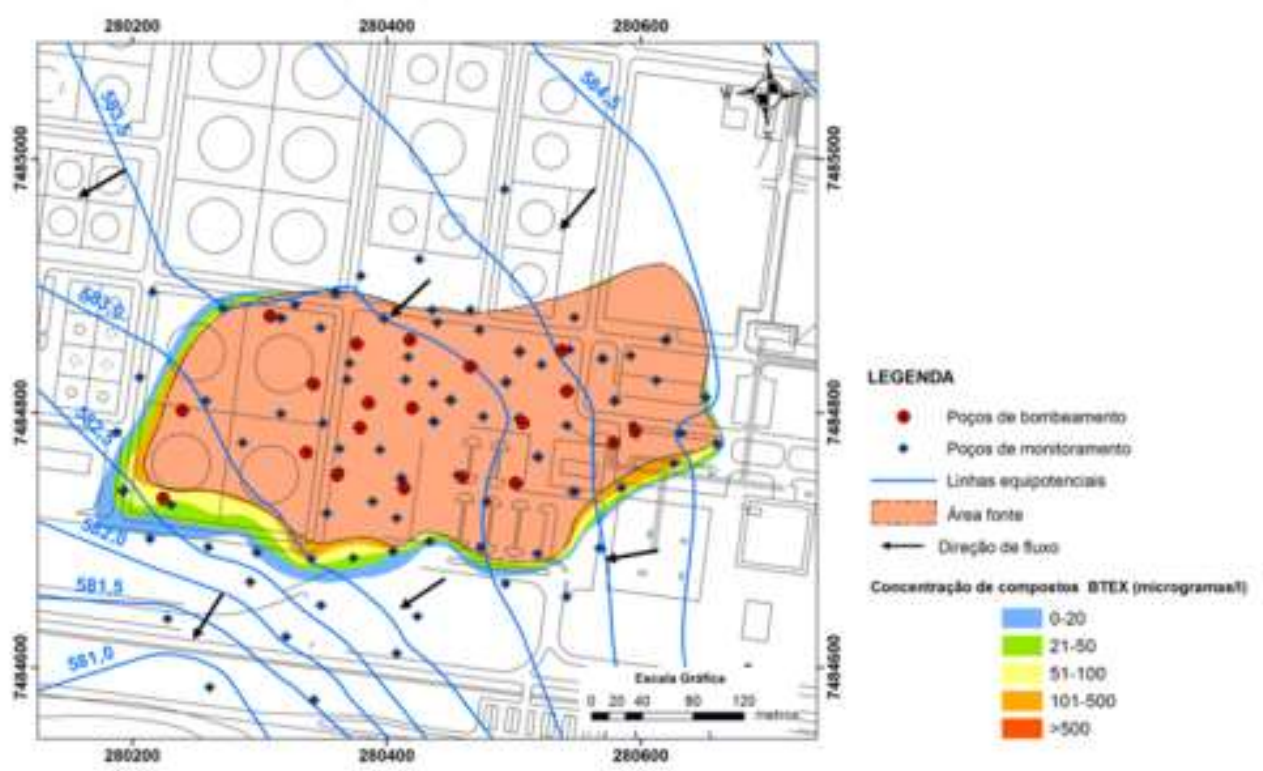

Figura 6 - Distribuição da pluma dissolvida de BTEX e poços de monitoramento e bombeamento existentes na área de estudo

Figure 6 - Distribution of the dissolved BTEX plume, and monitoring and pumping wells in the study are 
Como descrito por Pede (2009), o aquífero local é raso e predominantemente não confinado, composto por litologias diversas, como arenitos argilosos, arenitos microconglomeráticos e siltitos argilosos, depositados em um ambiente fluvial meandrante de idade cenozoica. A diversidade de litologias impõe uma forte heterogeneidade local, cujos valores de condutividade hidráulica, determinados por slug tests, variam de $1,09 \times 10^{-7} \mathrm{~m} / \mathrm{s}$ para lamitos até um máximo de $4,3 \times 10^{-4} \mathrm{~m} / \mathrm{s}$ para arenitos microconglomeráticos.

Face aos objetivos propostos, este trabalho foi segmentado em 3 etapas distintas, que estão descritas abaixo.

\section{Etapa 1 - Caracterização da área fonte}

Com o intuito de se avaliar a eficiência dos sitemas de remediação implantados bem como a evolução da contaminação, como descrito por Pede (2009) foi implantado um monitoramento do nível d'água e espessuras de fase livre nos poços de monitoramento com frequência quinzenal. De posse destas informações foi possível elaborar um mapa com variações de espessuras de fase livre em diferentes períodos.

Para avaliar a evolução das concentrações de compostos BTEX dissolvidos na água subterrânea foram coletadas amostras de água com frequência trimestral. Ressalta-se que as coletas foram empreendidas amostragens em poços situados na pluma de fase dissolvida e também na área fonte, quando estes poços não apresentassem fase livre em seu interior. O período em que se registrou o menor número de poços com fase livre em seu interior e possibilitou a amostragem de água subterrânea em quantidade significativa de poços foi registrado em Maio de 2012. Utilizou-se o cromatógrafo gasoso e o espectrômetro de massa acoplado a amostrador automático de headspace (GC/MS/HS), com limite de detecção de $1 \mathrm{mg} / 1$. Com o intuito de se determinar a quantidade de compostos aromáticos no LNAPL, Pede (2009) coletou amostras de querosene em onze poços distintos.

A determinação da quantidade compostos aromáticos e de alifáticos nas amostras de LNAPL, foram analisadas onze amostras representativas da extensão da pluma de fase livre. Utilizou-se o cromatógrafo gasoso e o espectrômetro de massa acoplado a amostrador automático de headspace (GC/MS/HS). A cromatografia gasosa tem por finalidade separar os compostos para posterior identificação; após separação, os compostos são analisados no espectrômetro de massa. Para cada análise utilizou-se $3 \mu \mathrm{L}$ da amostra de óleo, colocada posteriormente em um frasco lacrado contendo aproximadamente $0,18 \mathrm{~g}$ de sílica gel 60 Fluka, com limite de detecção de $5 \mathrm{~m} / \mathrm{l}$. Para a quantificação das amostras utilizou-se a técnica de fortificação com o padrão tridecano, com uma concentração de 1:7 (94,5 g.cm-3).

\section{Etapa 2 - Elaboração de um modelo conceitual}

Face aos resultados da caracterização da área fonte e seu comportamento ao longo do perído monitorado, foi elaborado um modelo conceitual, que explicasse algumas situações observadas em campo. A elaboração deste modelo foi subsidiado por resultados obtidos por informações disponíveis na literatura que contemplam os mecanismos que promovem a variabilidade da transferência de massa do hidrocarboneto em fase residual para a água subterrânea.

\section{Etapa 3 - Validação do Modelo Conceitual}

Para testar o modelo conceitual proposto, em âmbito teório, esforços foram empreendidos para se avaliar a consistência e apontar limitações às premissas levantadas a partir de informações disponíveis. A validação do modelo conceitual é mediado por 2 critérios:

a) Avaliar se os dados obtidos em campo obedecem às premissas presentes no modelo conceitual;

b) Em virtude do modelo conceitual assumir a existência da relação direta entre dois parâmetros distintos, avaliar a existência de correlação entre tais parâmetros, exibindo tendências apontadas pelas premissas adotadas.

Se estes dois critérios forem satisfatóriamente atendidos, é possível afirmar que as premissas adotadas são válidas e o modelo conceitual estabelecido é consistente, a despeito de incertezas ainda reinantes. A partir da validação do modelo conceitual estabelecido, são discutidas as implicações dos resultados aqui obtidos para o 
entendimento da evolução das concentrações de compostos BTEX, otimização dos sistemas de remediação.

\section{RESULTADOS}

\subsection{Caracterização da área fonte}

Como exposto pelo trabalho de Pede (2009) existem fortes variações na espessura de fase livre nos poços de monitoramento ao longo do tempo em razão do fenômeno de trapeamento e destrapemanto do LNAPL no meio poroso em razão da flutuação do nível d'água.
A Figura 7 ilustra as variações na espessura de fase livre nos poços de monitoramento ao longo do tempo, em função da alternância de períodos de trapeamento e destrapeamento do LNAPL no meio poroso. Em todos os períodos de monitoramento foi constatado que as maiores espessuras são registradas na porção central da área fonte $\mathrm{e}$ decrescem progressivamente para as bordas. Verifica-se, por exemplo, que em Novembro de 2006 (Figura 7A) que a espessura de fase livre excedeu $1,2 \mathrm{~m}$ na porção central da área fonte e declinou para alguns milimetros na borda. 
TERAMOTO, E.H.; PEDE, M.A.Z.; CHANG, K.H.

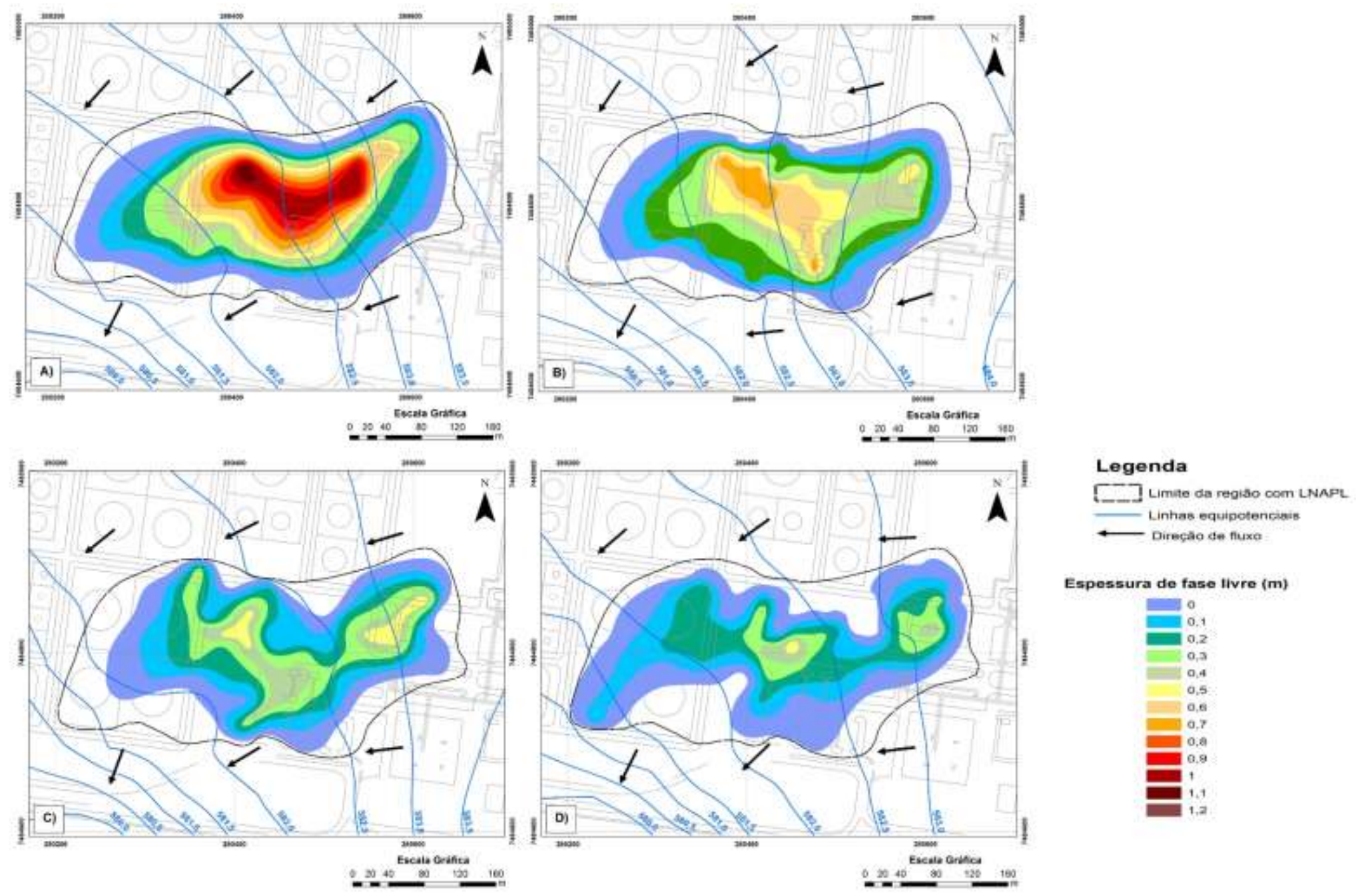

Figura 7 - Mapa de Espessura de fase livre nos poços de monitoramento para diferentes períodos. A) Novembro de 2006; B) Novembro de 2007; C) Setembro de 2009, D) Dezembro de 2010

Figure 7 - Map of free phase thickness in monitoring wells for various periods. A) November 2006; B) November 2007; C) September 2009; D) December 2010 
Utilizando os conceitos expostos por Chaberneau (2007), as espessuras de fase livre nos poços de monitoramento expressam indiretamente a quantidade de LNAPL presente no meio poroso. A partir das características físicas do querosene de aviação, do material geológico que contém o LNAPL e da espessura de fase livre nos poços de monitoramento, é possível determinar o perfil de saturação do LNAPL. As Figuras 8A e $8 \mathrm{~B}$ expressam o perfil de saturação teórico do querosene de aviação trapeado no meio poroso, empregando os parâmetros de entrada apresentados por Pede (2009). Ressalta-se que este modelo possui representatividade limitada frente à realidade, tendo em vista que não admite o efeito da histerese relacionado aos recorrentes ciclos de embebição e drenagem de água do meio poroso a partir da da flutuação do NA. Entretando, permite uma estimativa aproximada da quantidade de LNAPL presente no meio poroso. Assim, maiores espessuras de fase livre nos poços de monitoramento representam regiões com valores de saturação de LNAPL no meio poroso e, em oposição, espessuras reduzidas de fase livre nos poços de monitoramento indicam saturações baixas. Em razão disso, as maiores saturações de LNAPL estão presentes na porção central da área fonte e são reduzidas nas bordas.
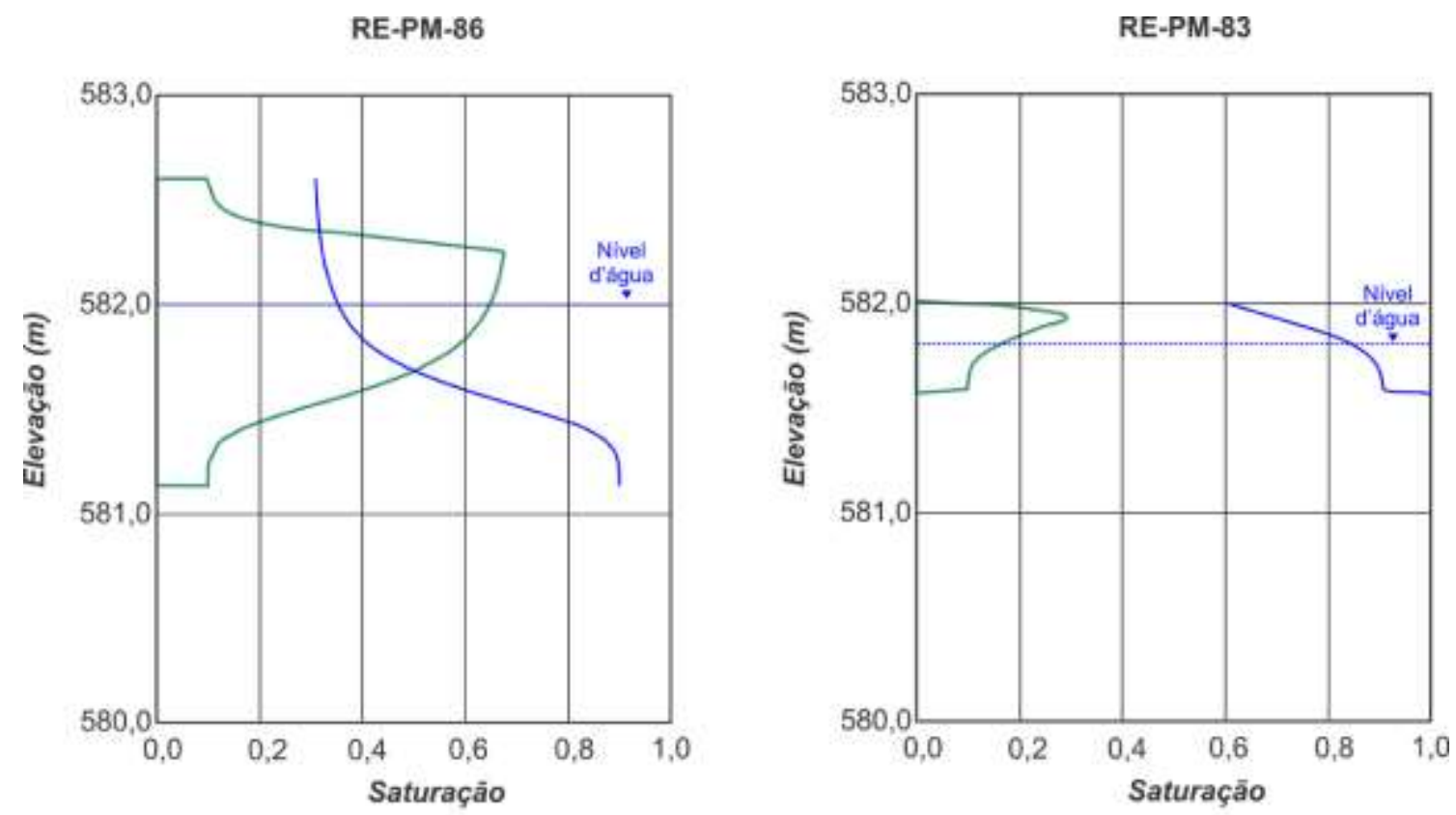

- Saturacăa do LNAPL (Sn)
- Saturaçáo da água (Sw)

Figura 8 - Perfil teórico de saturação para dois poços distintos com espessuras de fase livre de 1,03 m (esquerda) e 0,334 m (direita), empregando o modelo de Chaberneau (2007)

Figure 8 - Theoretical saturation profile for two different wells with free phase thicknesses of 1,03 m (left) and 0,334 m (right), using the model Chaberneau (2007)

A Figura 9 ilustra o mapa de isoconcentrações de compostos BTEX na área fonte para o período compreendido de Maio de 2012. Como é possível observar no referido mapa, as concentrações destes compostos declinam da região central da área fonte, onde alcança valores superiores a 3 $\mathrm{mg} / \mathrm{l}$, para as bordas, onde os valores são inferiores a $0,5 \mathrm{mg} / \mathrm{l}$.
Na Figura 10, está ilustrada o mapa de isoconcentrações de compostos aromáticos, soma dos poliaromáticos e monoaromáticos, nas amostras de querosene retirados de 11 poços de monitoramento distintos. Verifica-se que os maiores teores de compostos aromáticos são registrados na porção central e decrescem em direção à região marginal da área fonte. 


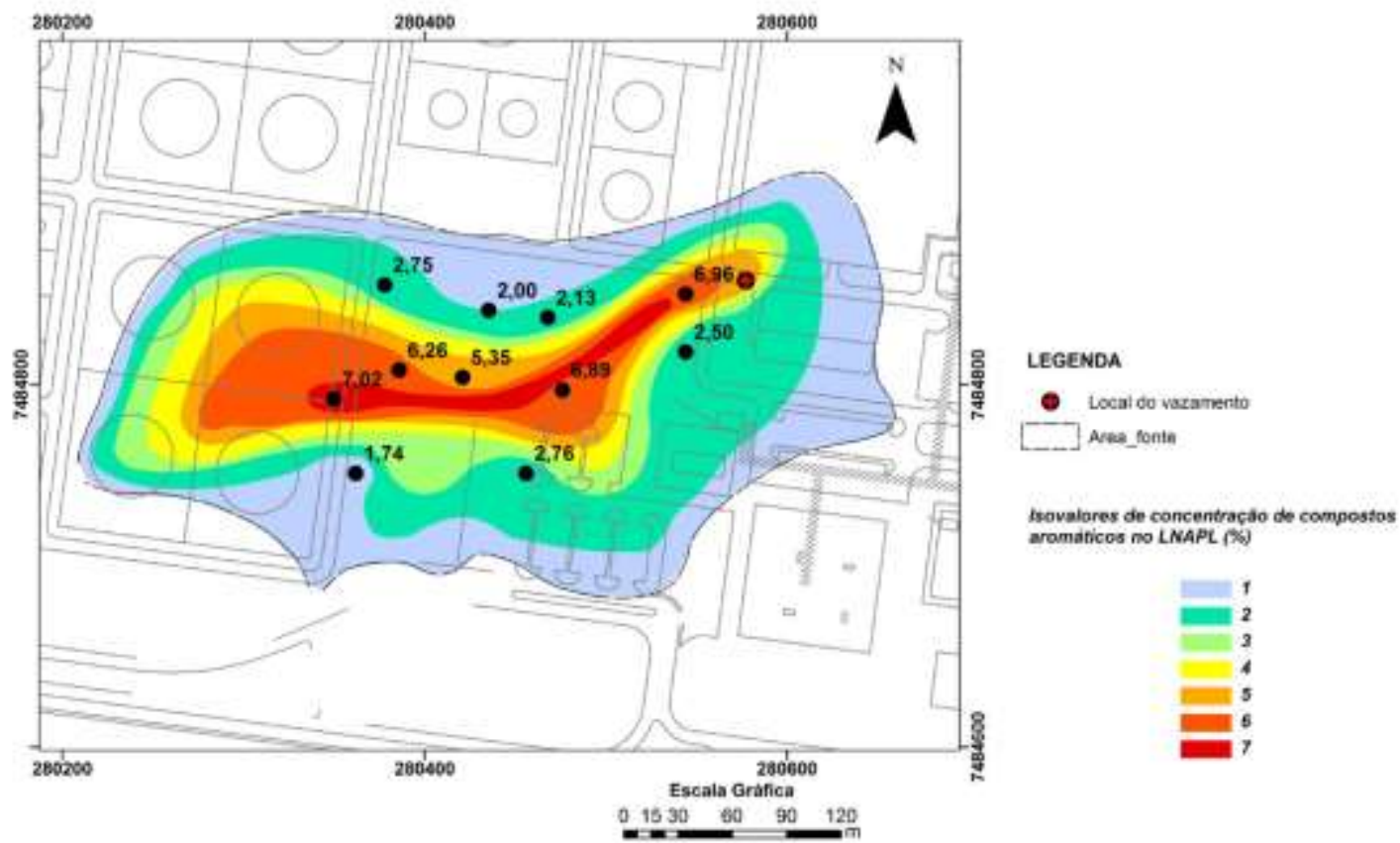

Figura 9 - Mapa das porcentagens de compostos aromáticos no LNAPL em Março de 2008 (extraído de Pede, 2009)

Figure 9 - Map showing the percentages of aromatic compounds in the LNAPL in March 2008 (extracted from Pede, 2009)

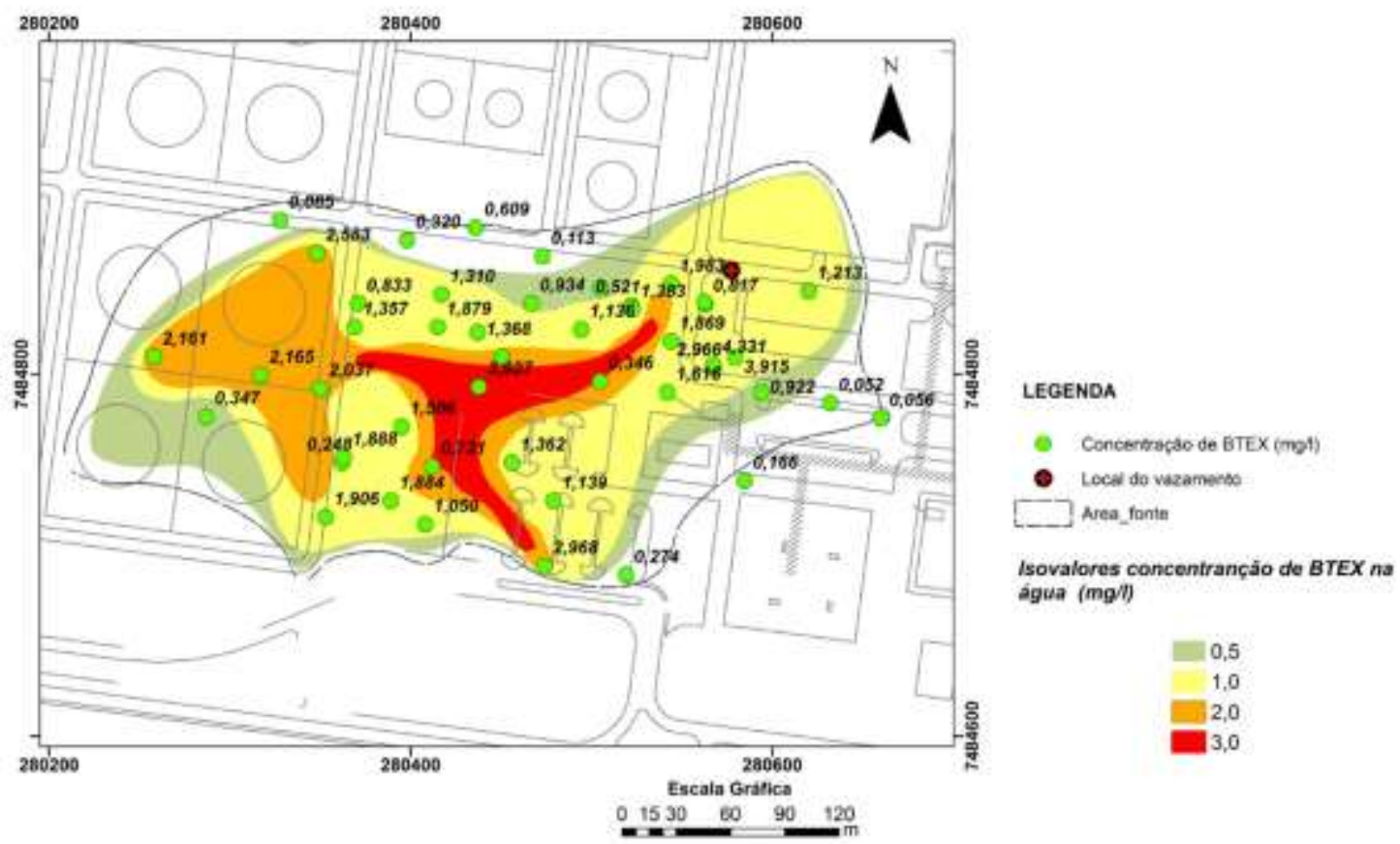

Figura 10 - Concentração de compostos BTEX mensurados em poços situados na área fonte.

Figure 10 - Concentration of BTEX compounds in wells located in the source area.

\subsection{Modelo Conceitual Proposto}

Uma análise comparativa dos mapas de espessuras de fase livre no poços de monitoramento, apresentados nas Figuras 7A-
7D, isoconcentrações de BTEX na água subterrânea, expostos na Figura 9 e teor de aromáticos no LNAPL, expostos na Figura10, demonstram a existência de tendências similares. Nestes mapas visivelmente existem 
tendência dos valores observados se encontram na porção central e declinam progressivamente para as regiões marginais. A constatação destas tendências similares sugere a existência de uma relação genética entre estes parâmetros. Com o intuito de explicar a relação entre os parâmetros mencionados na etapa de caracterização da área fonte, foi proposto um modelo conceitual, a partir de premissas e conceitos presentes na literatura para correlacionar estes diferentes parâmetros.

Com exposto no trabalho de Chaberneau (2007), a espessuras de fase livre nos poços de monitoramento permitem inferir a saturação de LNAPL no meio poroso. Nexte contexo, a região central da área fonte representa porções do aquífero com saturações de LNAPL residual ao passo que as regiões marginais reprsentam regiões com baixa saturação. Neste caso, supõe-se que na região central da área fonte face ao elevado grau de saturação de LNAPL, este se distribua como lentes continuas ao passo que nas regiões marginais, o LNAPL se distribua como gotículas isoladas. Uma vez que anw se correlaciona diretamente com o $\mathrm{Sw}$, a expectativa é que na região central da área fonte, anw seja reduzido em comparação com a região marginal desta. Em virtude disto, espera-se que exista uma perda de massa menos expressiva para a água nas bordas da área dotados de valores mais expressivos de anw quando comparados com a região central dotado de valores reduzidos deste parâmetro.

A Figura 11 ilustra conceitualmente a evolução da concentração da água em contato com o LNAPL para dois valores distintos de anw com informações hipotéticas de concentração e coeficientes de transferência de massa. Observa-se que em uma condição inicial, a transferência de massa seja mais efetiva em uma condição com valores mais elevados de anw e, deste modo, as concentrações de compostos BTEX na água mais elevadas. Contudo, em virtude da perda de massa mais intensa para a água, regiões com valores elevados de anw tornam-se mais precocemente depletados em compostos monoaroamáticos, o que induz à um decréscimo no gradiente de concentração entre o NAPL e a água. Com o decréscimo no gradiente de concentração quantidades menores de BTEX são transferidos para água que resulta em menores concentrações destes compostos na água.

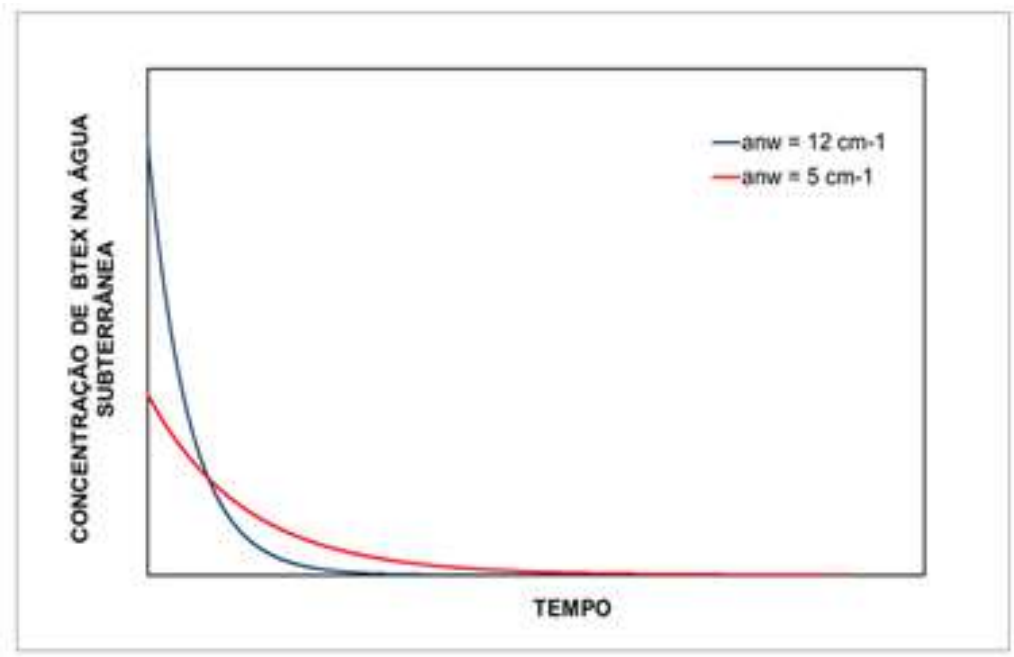

Figura 11 - Variação temporal de concentração de compostos BTEX em função da transferência de massa do NAPL para a água em duas situações com valores de anw distintos

Figure 11 - Temporal variation of the BTEX concentration compounds according NAPL mass transfer to the water in two situations with different values of anw

\subsection{Validação do Modelo Conceitual Proposto}

Se as premissas contidas no Modelo Conceitual proposto forem verdadeiras, existe uma relação direta entre a massa de BTEX na água subterrânea e a quantidade compostos aromáticos no LNAPL residual, uma vez que este encontra-se menos depletado nestes 
compostos. Dos onze poços amostrados, foi possível a coleta de água subterrâne em apenas 5 poços, uma vez que os restantes apresentavam fase livre no interior do poço no momento da coleta. A Figura 12 ilustra uma análise de regressão com ajuste não-linear entre as concentrações de BTEX na água subterrânea e a porcentagem de compostos aromáticos no LNAPL e indica uma relação direta entre a quantidade de compostos aromáticos no LNAPL e a concentração de compostos BTEX na água subterrânea. Ressalta-se que embora a análise de regressão contida neste gráfico não seja consistente do ponto de vista estatístico, em virtude da incipiência na quantidade de amostras, ao menos expressa claramente uma relação de dependência entre os parâmetros analisados.

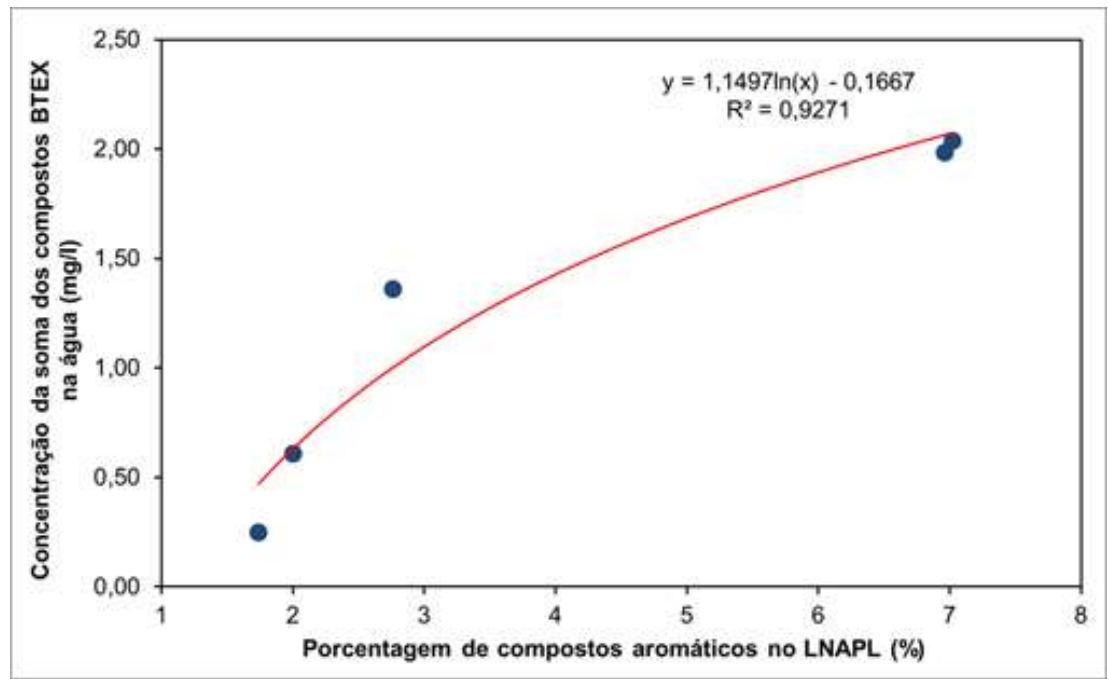

Figura 12 - Dispersão dos valores estimados de concentração dos compostos BTEX em águas subterrâneas na área fonte.

Figure 12 - Dispersion of the estimated values of BTEX compounds concentration in groundwater at the source.

A principal premissa do modelo conceitual proposto é que a massa de BTEX se depletará mais rapidamente onde o LNAPL está distribuído na forma de gotículas isoladas, em porções com baixa saturação de LNAPL. Na direção oposta, é esperado uma perda mais lenta de massa de BTEX em porções onde o LNAPL se distrui de maneira mais contínua, exibindo saturações mais elevadas de LNAPL. Se as premissas aqui apresentadas forem verdadeiras, os resultados do monitoramento contínuo das concentrações de compostos BTEX apresentará uma tendência clara de declínio em poços situados na região marginal em comparação com a região central da área fonte ao longo do período monitorado. As Figuras 13 e 14 ilustram a evolução da concentração de compostos BTEX na região marginal da área fonte e exibem tendência nítidas de declínio segundo uma função exponencial, descrevendo um decaimento de primeira ordem. Por outro lado, as Figuras 15 e 16 ilustram as concentrações de compostos BTEX na região central da área fonte $\mathrm{e}$ demonstram a inexistência tendências de declínio ao longo do tempo, fato que pode ser atestado pelo valor de coeficiente de determinação $\left(R^{2}\right)$ reduzido para um ajuste expontencial. Deste modo, é possível atestar que o modelo conceitual proposto permite explicar satisfatórimente as variações na transferência de massa do LNAPL residual para a água. Os resultados aqui apresentados indicam que o modelo conceitual proposto está calcado em premissas consistentes e explicam satisfatoriamente a perda diferencial de massa de BTEX em razão das variações de saturação de LNAPL. 
Modelo conceitual para explicar a depleção heterogênea de compostos btex em uma área contaminada por querosene de aviação

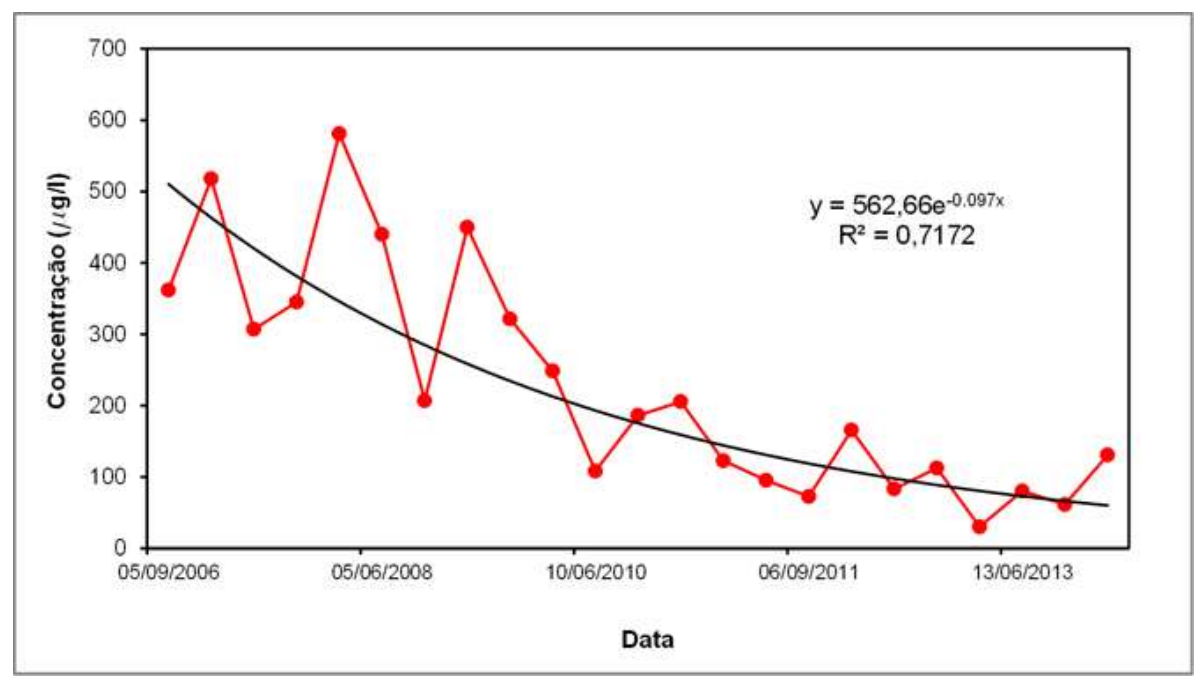

Figura 13 - Variação da concentração dos compostos BTEX em função do tempo na região limítrofe da área fonte, exibindo clara tendência de queda exponencial (decaimento de primeira ordem)

Figure 13 - Variation of the concentration of BTEX compounds versus time in the border region of the source area, showing clearly the exponential downward trend (first order decay)

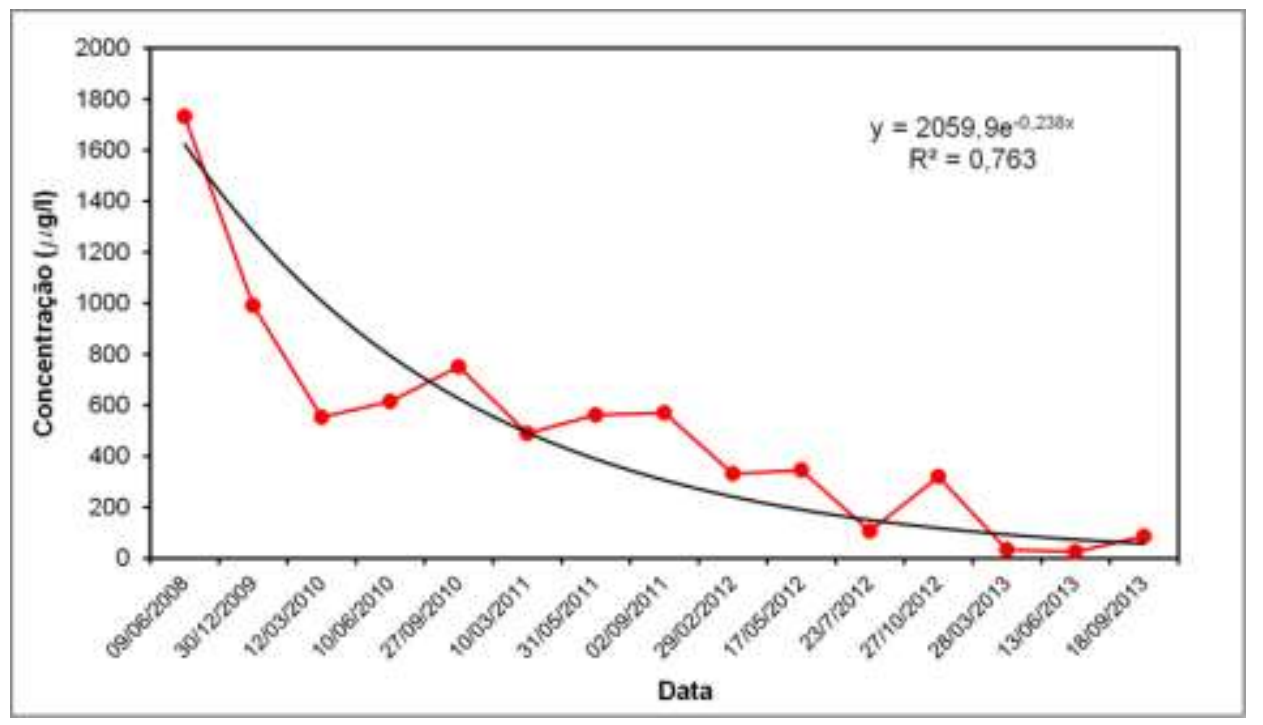

Figura 14 - Variação da concentração dos compostos BTEX em função do tempo na região limítrofe da área fonte, exibindo clara tendência de queda exponencial (decaimento de primeira ordem)

Figure 14 - Variation of the concentration of BTEX compounds versus time in the border region of the source area, showing clearly the exponential downward trend (first order decay) 


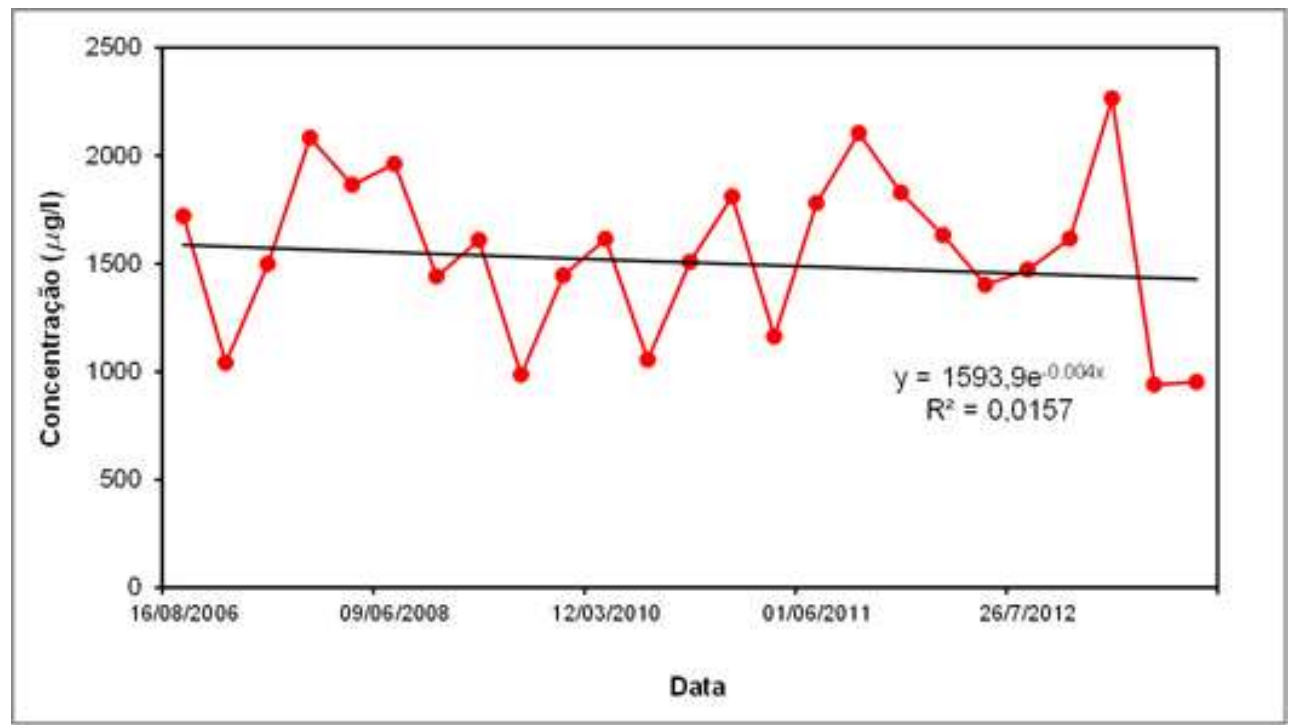

Figura 15 - Variação da concentração dos compostos BTEX em função do tempo na porção central da área fonte, não exibindo tendências de queda

Figure 15 - Variation of the concentration of BTEX compounds function of time in the central portion of the source area, exhibiting no decrease trend

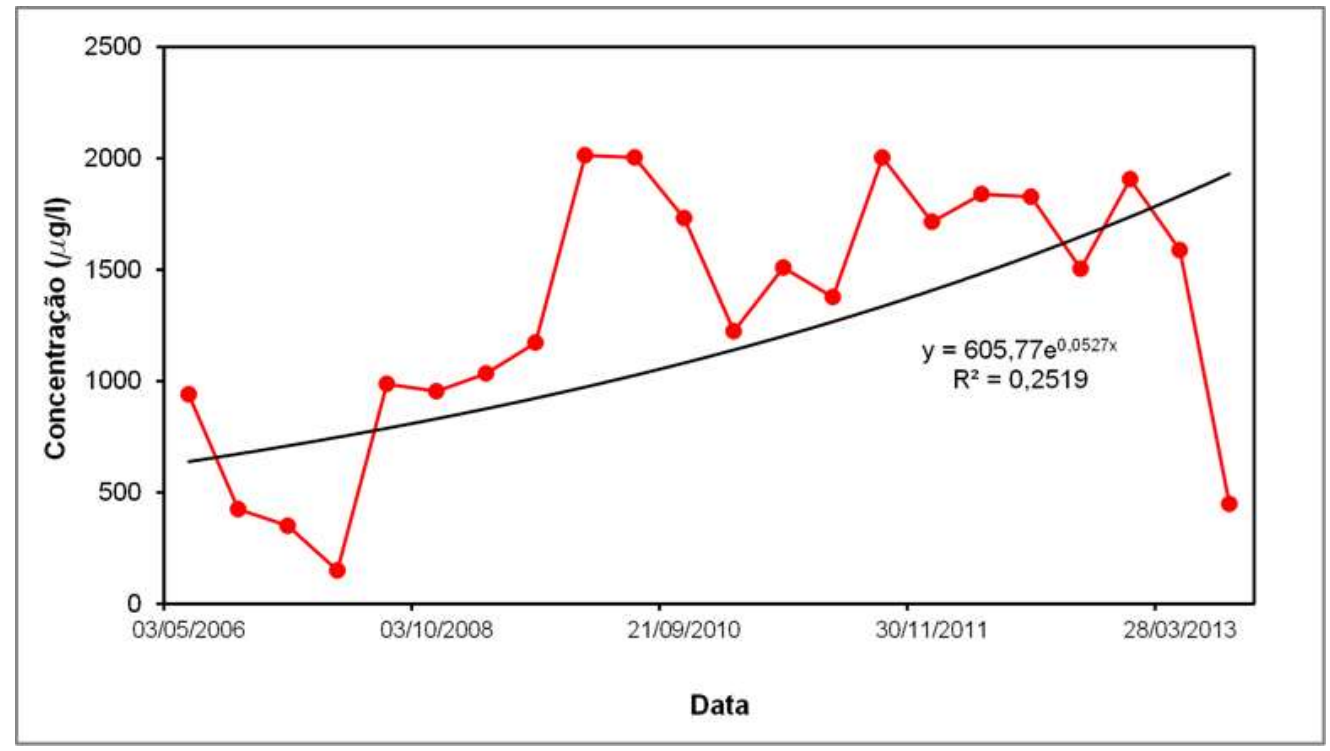

Figura 16 - Variação da concentração dos compostos BTEX em função do tempo na porção central da área fonte, não exibindo tendências de queda

Figure 16 - Variation of the concentration of BTEX compounds function of time in the central portion of the source area, exhibiting no decrease trend

Tendo em vista a necessidade de se quantificar a massa de BTEX ainda remanescente em subsuperfície para fins de atenuação natural, otimização dos sistemas de remediação por técnicas baseadas no pumpand-treat, quantificação mais precisa das análises de risco. As condições de contorno empregados em modelos matemáticos de transporte de solutos para prever o comportamento da pluma dissolvida e calculo de balanço de massa devem representar a realidade aqui exposta para uma representação mais acurada das condições reais.

\section{CONCLUSÕES}

Embora as relações aqui apontadas tenham sido evidenciadas na literatura, nenhum trabalho até o presente momento, havia demonstrado a existência de uma tendência de depleção heterogênea do LNAPL no que se refere aos compostos monoaromáticos. A 
partir de evidências de campo, que existe uma perda mais expressiva de massa em relação à região central da área fonte. As evidências apresentadas atestam que o modelo conceitual formulado em âmbito teórico explica em grande parte o comportamento observado em condições de campo. O mapa de porcentagem de aromáticos no LNAPL, espessura de fase livre nos poços de monitoramento e concentração dos compostos BTEX na área fonte apresentam uma nítida tendência de decréscimo do centro para as bordas, indicando que tais parâmetros são diretamente relacionados. No entanto, relata-se a impossibilidade de estabelecer uma relação quantitativa entre tais parâmetros decorrentes das dificuldades de se parametrizar os valores realistas de saturação, pressão capilar e distribuição detalhada das heterogeneidades litológicas.

Os recorrentes ciclos de embebição e drenagem de água e LNAPL no meio poroso são ocasionados pela flutuação do nível d'água. Tal ciclidade interfere nas taxas de transferência de BTEX para a água subterrânea e variações sazonais devem ser esperadas. A ci-

\section{REFERÊNCIAS}

AMERICAN PETROLEUM INSTITUTE. API, Interactive LNAPL Guide, Version 2.0. Version 2.0 User Guide for Data Retrieval, API Publication n. 4731, 2004.

ANDERSON, M.R.; JOHNSON, R.L.; PANKOW, J.F. Dissolution of dense chlorinated solvents into ground-water : 1. Dissolution from a well-defined residual source. Ground Water. v. 30, n. 2, p. 250-256, 1992.

BRADFORD, S. A.; LEIJ, F. J. Estimating interfacial areas for multifluid soil systems, Journal of Contamiant Hydrology, v. 27, p. 83-105, 1997.

BRUSSEAU, M. L.; NARTER. M.; SCHNAAR, S.; MARBLE, J. Measurement and estimation of organic liquid/water interfacial areas for several natural porous media. Environmental Science Technology. v. 43, p. 3619-3625, 2009.

CHARBENEAU, R.J. LNAPL distribution and recovery model (LDRM). API Publication Number 4760, American Petroleum Institute, Washington D.C., 2007. nética de dissolução do LNAPL para a água não é constante em toda a área fonte e, sim, dependente do grau de saturação deste fluido no meio poroso.

As observações de campo, ainda que em caráter preliminar, têm fortes implicações para o entendimento do comportamento da dissolução de compostos solúveis na área fonte e, consequentemente, no balanço de massa, modelagem de transporte, comportamento da fase dissolvida e elaboração dos planos de remedição. Contudo, ressalta-se que a compreensão do modelo conceitual aqui proposto deve ser aprimorada e experimentos in situ e laboratoriais devem ser conduzidos para tal fim. Com base nos resultados aqui apresentados, ressalta-se a necessidade de coletar um número maior de amostras de LNAPL para quantificação dos compostos aromáticos, sobretudo os monoaromáticos, investigações com LIF (Laser Induced Fluorescence) para determinação da quantidade de QAV trapeado no meio poroso, somado a ensaios de curva de retenção capilar e modelos matemáticos de fluxo multifásicos.

CHEN, D.; PYRAK-NOLTE, L.J.; GRIFFIN, J.; GIORDANO, N.J. Measurement of interfacial area per volume for drainage and imbibition. Water Resources Research. v.43, p. 1-6, 2007.

CHO, J.; ANNABLE, M. D. Characterization of pore scale NAPL morphology in homogeneous sands as a function of grain size and NAPL dissolution. Chemosphere. v. 61, p. 899-908. 2005.

DODSON, R.; SCHROTH, M.H.; OOSTROM, M.; ZEYER, J. Determination of NAPL-water interfacial areas in well-characterized porous media. Environmental Science Technology, v.40, n.3, p. 815-822, 2006.

FARR, A. M.; HOUGHTALEN, R. J.; McWHORTER. Volume estimation of light nonaqueous phase liquids in porous media. Ground Water, v.28, n. 1, p. 48-56, 1990.

FERNANDES, A. J. Tectônica Cenozóica na Porção Media da Bacia do rio Piracicaba e sua Aplicação à Hidrogeologia. 1997. 244 f. Tese de Doutoramento em Recursos Minerais e Hidrogeologia) - Instituto de Geociências, Universidade de São Paulo - São Paulo. 
GRANT, G.P.; GEHARD, J.I. Simulation the dissolution of a complex dense nonaqueous phase liquids source zone: 1 . Model to predict interfacial area. Water Resources Research. v. 43. p.. 1-14. 2007.

HELD, R.J.; CELIA, M.A. Modeling support of functional relationships between capillary pressure, saturation, interfacial area and common lines. Advances in Water Resources, v.. 24, p. 325343, 2001

JEONG, J.; CHARBENEAU, R.J. An analytical model for predicting LNAPL distribution and recovery from multi-layered soils. Journal fo Contaminant Hydrology, v. 156, n.1, p.. 52-61, 2014.

KECHAVARZI, C.; SOGA, K.; ILLANGASEKARE, T. H. Two-dimensional laboratory simulation of LNAPL infiltration and redistribution in the vadose zone. Journal of Contamiant Hydrology, v. 76, p. $211-233,2005$.

LENHARD, R.J J.C PARKER. Estimation of free product hydrocarbon volume from fluid level in monitoring wells. Ground Water, v. 28; p. 57-67, 1990.

LENHARD, R.J.; JOHNSON, T.G.; PARKER, J.C. Experimental observations of nonaqueousphase liquid subsurface movement. Journal of Contaminant Hydrology, v. 12, n. 1-2, p. 79101. 1993.

MERCER, J. W.; COHEN, R.M. A review of immiscible fluids in the subsurface: Properties, models, characterization and remediation. Journal of Contaminant Hydrology, v. 6, p. 107-163, 1990.

MILLER. C.T.; POIRIER-MCNEILL， M.M.; Mayer, A.S. Dissolution of trapped nonaqueous phase liquids: Mass transfer characteristics. Water Resources Research, v. 26, n. 11, p. 2783-2796, 1990.
OOSTROM, M.; WHITE, M. D.; BRUSSEAU, M. L. Theoretical estimation of free and entrapped nonwetting-wetting fluid interfacial areas in porous media. Advances in Water Resources, v. 24, p. 887-898, 2001.

PEDE, M. A. Z. Flutuação do lençol freático e sua implicação na recuperação de hidrocarbonetos: um estudo de caso. Tese de Doutorado em Geociências e Meio Ambiente. 2009.

POWERS, S.E.; ABRIOLA, L.M.; WEBER. W.J., An experimental investigation of NAPL dissolution in saturated subsurface systems: transient mass transfer rates. Water Resources Research, v. 30, n. 2, p. 321- 332. 1994.

POTTER, M.L.; WILDESHCHILD, D.; GRAN, G.; GERHARD, J.I. Measurement and prediction of the relationship between capillary pressure, saturation, and interfacial area ina a NAPL-waterglass bead system. Water Resources Reserarch, v.1. 46, n. 1, p. 1-10, 2010.

SABA, T., $E$ ILLANGASEKARE, T.H. Effect of groundwater flow dimensionality on mass transfer from entrapped nonaqueous phase liquid contaminants, Water Resources Research, v. 36, p. 971979. 2000.

SOGA, K.; PAGE, J.W.E.; ILLANGASEKARE, T.H. A review of NAPL source zone remediation efficiency and the mass flux approach. Journal of Hazard Materials, v. 110, p. 13-27, 2004.

VAN GENUCHTEN, M. T. A closed-form equation for predicting the hydraulic conductivity of unsaturated soils. Soil Science Society American Journal, v. 44, n. 5, p. 892 - 898, 1980.

WANG, W.; KUO, T. Effect of precipitation on LNAPL recovery performance: An integration of laboratory and field results. Journal of Petroleum Science and Engineering. v. 116, n. 1, p. 1-7, 2014. 